\title{
Espécies da caatinga para uso em cortinas de segurança contra incêndios florestais
}

Os incêndios florestais causam inúmeros impactos socioambientais no Brasil e no mundo. A implantação de cortinas de segurança impede a propagação de um incêndio na propriedade e auxilia nas técnicas de combate. Assim, objetivou-se nesta pesquisa, avaliar a inflamabilidade de plantas da Caatinga e sua eficiência como cortinas de segurança na prevenção de incêndios florestais no semiárido paraibano. A pesquisa foi desenvolvida em campo e em laboratório. Em campo, a queima ocorreu em parcelas experimentais de $1 \mathrm{~m} 2$ contendo $2 \mathrm{~kg}$ de material combustível cactáceas, folhosas e acículas de pinus, no qual determinou-se a espessura e volume da manta, umidade do material, frequência e tempo de ignição, tempo de queima, altura da chama, velocidade de propagação, intensidade do fogo, índice de combustibilidade e de severidade, temperatura do material combustível e do solo. No laboratório foi determinado o teor de cinzas e o poder calorífico superior. As cactáceas (Opuntia sp, Cereus jamacaru, Pilosocereus gounellei) apresentaram maiores tempos de ignição e menores tempos de combustão, sendo queimados somente os espinhos. A faveleira (Cnidoscolus quercifolius) não deferiu das cactáceas com relação ao tempo de combustão. $O$ pereiro (Aspidosperma pyrifolium) e a Catingueira (Cenostigma bracteosum) apresentaram índice de severidade modernamente alto, em função do elevado poder calorífico do lenho. As cactáceas e a faveleira apresentaram menores valores de poder calorífico, sendo recomendadas para uso em cortinas de segurança. 0 pereiro e a catingueira apresentaram diferenças na inflamabilidade entre as partes constituintes das plantas, não sendo recomendadas como cortinas de segurança.

Palavras-chave: Incêndios florestais; Silvicultura Preventiva; Comportamento do fogo; Material combustível florestal.

\section{Caatinga species for use in safety curtains against forest fires}

\begin{abstract}
Forest fires cause numerous social and environmental impacts in Brazil and worldwide. Implementing safety curtains prevents the spread of a fire and helps in firefighting techniques. Thus, the aim of this research was to evaluate the flammability of Caatinga plants and their efficiency as safety curtains to prevent forest fires in the Paraíba semiarid. This research was developed in the field and in the laboratory. In the field, burning occurred in $1 \mathrm{~m} 2$ experimental plots containing 2 $\mathrm{kg}$ of cacti, hardwood fuel material and pine needles, in which the thickness and volume of the blanket, material humidity, frequency and ignition time, burning time, flame height, propagation speed, fire intensity, combustibility and severity index, temperature of combustible material and soil were determined. In the laboratory, the ash content and the higher calorific value were determined. The species cacti (Opuntia sp, Cereus jamacaru, Pilosocereus gounellei) showed longer ignition times and shorter combustion times, being burned only the thorns. The specie Cnidoscolus quercifolius did not differ from cacti in their burning time. The specie Aspidosperma pyrifolium and the Cenostigma bracteosumpresented moderately higher severity index due to the high calorific value of the wood. Cacti and C. quercifolius presented lower calorific power, being recommended for use in safety curtains. Aspidosperma pyrifolium and Cenostigma bracteosumshowed differences in flammability between the constituent parts of the plants, not being recommended as safety curtains.
\end{abstract}

Keywords: Forest fires; Preventive Silviculture; Fire behavior; Forest flammable material.

Topic: Ciências Florestais

Reviewed anonymously in the process of blind peer.
Received: 10/05/2020 Approved: 04/06/2020
Alexandro Dias Martins Vasconcelos (D) Universidade Federal de Campina Grande, Brasil http://lattes.cnpq.br/1121323366922441 http://orcid.org/0000-0002-6795-1121 alexandrodmv@hotmail.com

Patrícia Carneiro Souto (D) Universidade Federal de Campina Grande,

Brasil
http://lattes.cnpq.br/1011605644046440 http://orcid.org/0000-0003-4631-5342 pcarneirosouto@yahoo.com.br

Arliston Pereira Leite (iD)

Universidade Federal da Paraíba, Brasil Universidade Federal da Paraiba, Brasil http://lattes.cnpq.br/3807917267599115 arlistonpereira@hotmail.com

\begin{tabular}{|l} 
Andreza Ferreira Guedes 1 UD \\
Universidade Federal de Campina Grande, \\
Brasil \\
$\frac{\text { http://lattes.cnpq.br/8723083566764043 }}{\text { http://orcid.org/0000-0002-2633-8793 }}$ \\
$\underline{\text { andreza.cbio@gmail.com }}$ \\
Valdirene Henrique Nunes 10 \\
Universidade Federal de Campina Grande, \\
Brasil \\
$\frac{\text { http://lattes.cnpq.br/5760770413614292 }}{\text { http://orcid.org/0000-0003-4019-2601 }}$ \\
$\underline{\text { valdirene_nunes16@hotmail.com }}$ \\
Sérvio Túlio Pereira Justino (D) \\
Universidade Federal de Campina Grande, \\
Brasil \\
http://lattes.cnpq.br/6435440748550629 \\
$\underline{\text { http://orcid.org/0000-0003-1029-7808 }}$ \\
serviojustino@outlook.com
\end{tabular}

\begin{tabular}{|l} 
Ramon Medeiros da Silva \\
Universidade Federal de Campina Grande, \\
Brasil \\
$\frac{\text { http://lattes.cnpq.br/57942222445125835 }}{\text { http://orcid.org/0000-0002-5276-9845 }}$ \\
\hline medeiros.mocambo@gmail.com \\
Gabriela Gomes Ramos (1D \\
Universidade Federal de Campina Grande, \\
Brasil \\
http://lattes.cnpq.br/6008244081281390 \\
http://orcid.org/0000-0002-2028-1503 \\
gabiengflorestal@gmail.com \\
Jacob Silva Souto@ 10 \\
Universidade Federal de Campina Grande, \\
Brasil \\
http://lattes.cnpq.br/936223692797079 \\
http://orcid.org/0000-0002-9787-8623 \\
jacob_souto@yahoo.com.br
\end{tabular}

Robson José de Oliveira (DD Universidade Federal do Piauí, Brasil http://lattes.cnpq.br/2371730431088108 http://orcid.org/0000-0002-6439-9693 robson_ufpi@yahoo.com.br

\section{Referencing this:}

VASCONCELOS, A. D. M.; SOUTO, P. C.; LEITE, A. P.; GUEDES, A. F.; NUNES, V. H.; JUSTINO, S. T. P.; SILVA, R. M.; RAMOS, G. G.; SOUTO, J. S.; OLIVEIRA, R. J.. Espécies da caatinga para uso em cortinas de segurança contra incêndios florestais. Revista Ibero Americana de Ciências Ambientais, v.11, n.4, p.1-20, 2020. DOI: http://doi.org/10.6008/CBPC2179-6858.2020.004.0001

DOI: 10.6008/CBPC2179-6858.2020.004.0001 


\section{INTRODUÇÃO}

Os incêndios florestais causam inúmeros impactos socioambientais no Brasil e no mundo, contribuindo com aumento nas emissões de $\mathrm{CO}_{2}$, com o surgimento de doenças respiratórias, perda da fertilidade e desparecimento dos microrganismos do solo, eliminação da matéria orgânica, alteração da paisagem, mortalidade de árvores e demais componentes vegetacionais, diminuição do fluxo gênico no meio e também interferência no setor econômico.

A origem dos incêndios florestais pode ocorrer de forma intencional, acidental ou natural, consumindo o material combustível presente no ambiente. $O$ fogo origina-se da combinação de três elementos: o oxigênio, o material combustível e o calor, que constituem o triângulo do fogo e que juntos iniciam o processo de combustão; caso contrário, não se origina a combustão ou a mesma pode ser interrompida (SOARES et al., 2007). Desta forma, denomina-se incêndio florestal a ocorrência do fogo sem controle, originado de forma conhecida ou não sobre a vegetação, com ampla ocorrência e intensidade capaz de provocar desastres no meio.

As condições climáticas, como a umidade relativa do ar, a temperatura, a velocidade do vento está inteiramente relacionada à ocorrência e propagação dos incêndios florestais, tornando-se, por tanto, fatores essenciais na prevenção e combate dos mesmos (NUNES, 2005). Esses fatores contribuem para uma maior ocorrência de incêndios na Caatinga, uma vez que estão associados ao longo período de seca na maior parte do ano. Acrescente-se a esse aspecto o tipo de vegetação caducifólia, que se transforma em material combustível seco e propício à ocorrência de incêndio florestal.

As cortinas de segurança, são medidas silviculturais importantes na prevenção ou impedimento da propagação do fogo, principalmente em áreas de vulnerabilidade aos incêndios florestais, como, por exemplo, as áreas que acumulam material combustível em determinadas épocas do ano. Essa técnica consiste em dispor no campo o plantio, em fileiras ou em faixas, de uma ou mais espécies de baixa inflamabilidade que impeça, retarde ou dificulte a propagação do fogo, evitando danos econômicos e ambientais (SOARES, 2000).

A implantação das cortinas de segurança impede a propagação de um incêndio na propriedade e auxilia nas técnicas de combate pela brigada. Por esse motivo, torna-se importante conhecer a inflamabilidade das espécies, uma vez que as mesmas podem proporcionar um controle sobre os incêndios florestais, tornando-se fundamental estudar as principais características das espécies como o poder calorífico, a inflamabilidade e o comportamento do fogo.

As cortinas de segurança também podem proporcionar, além de proteção às propriedades rurais, proteção às áreas de restauração, experimentos científicos com plantios perenes ou anuais, áreas de preservação permanente, reservas legais e áreas de preservação ambiental, desde que as espécies não prejudiquem o equilíbrio natural dessas áreas.

No Brasil, estudos relacionados com avaliação do potencial de espécies como cortinas de segurança ainda são 'insólitos', sobretudo, em regiões semiáridas do nordeste do brasileiro. O semiárido brasileiro se 
encontra inserida no bioma Caatinga, que é constituída de elevado endemismo de plantas e animais exclusivamente brasileiros. Assim, esse tipo de estudo pode estabelecer resultados importantes no meio ecológico, econômico e social, por meio de espécies vegetais como cortinas de segurança, podendo garantir a proteção de empreendimentos, áreas em recuperação ambiental, manutenção e conservação da flora e da fauna, em áreas vulneráveis aos incêndios florestais, contribuindo para o manejo e sustentabilidade dos recursos naturais. Assim, objetivou-se, nesta pesquisa, avaliar a inflamabilidade de plantas da Caatinga e sua eficiência como cortinas de segurança na prevenção de incêndios florestais no semiárido paraibano.

\section{MATERIAIS E MÉTODOS}

\section{Caracterização da área de estudo}

A pesquisa foi desenvolvida na cidade de Patos-PB, localizada no Sertão Paraibano, com altitude média de $250 \mathrm{~m}$, entre as coordenadas $07^{\circ} 01^{\prime} 32^{\prime \prime}$ Sul e $37^{\circ} 16^{\prime} 40^{\prime \prime}$ Oeste (Figura 1). 0 clima da região, segundo a classificação de Köppen (ALVARES et al., 2014), é do tipo BSh, quente e seco, com duas épocas definidas, uma chuvosa e outra seca.

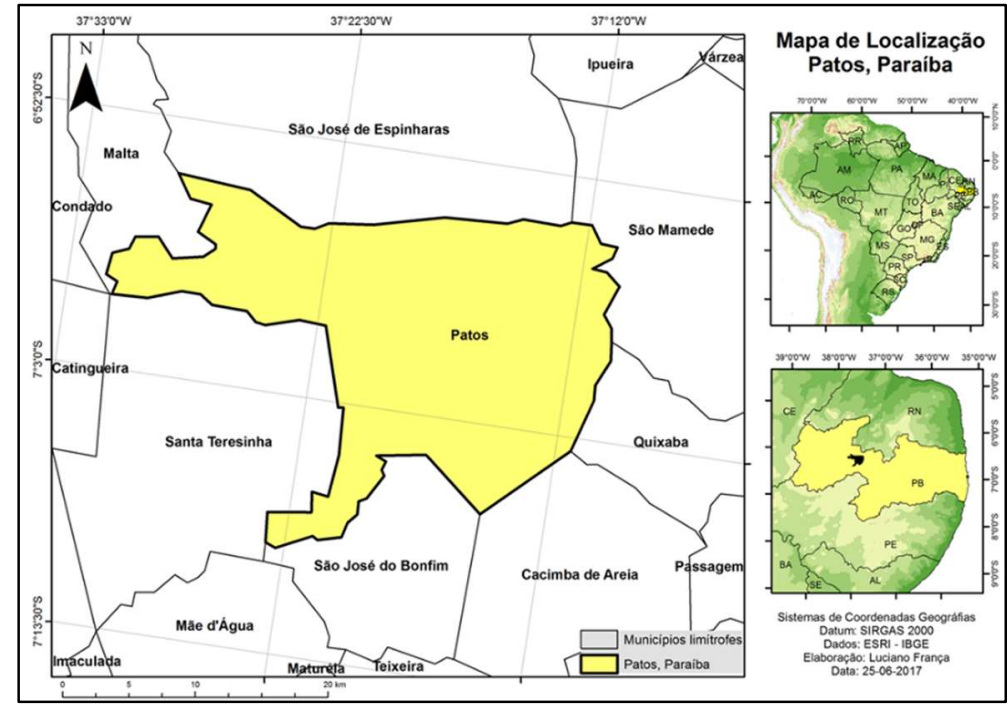

Figura 1: Mapa de localização, com destaque no município de Patos/PB

Apresenta precipitação média anual de $600 \mathrm{~mm}$, temperatura média de $30 \circ \mathrm{C}$ e umidade relativa do ar em torno de 55\%. Os solos predominantes na região são classificados como Luvissolos Crômicos e Neossolos Litólicos, ricos em nutrientes, porém com forte limitação física e de pequena espessura.

\section{Delineamento e Procedimento Experimental}

O experimento foi conduzido no Viveiro Florestal da Universidade Federal de Campina Grande, Campus de Patos/PB. Utilizou-se delineamento em blocos casualizados, com sete tratamentos representados pelas diferentes espécies da Caatinga, dispostas em quatro blocos. Para o presente estudo, foram selecionadas três espécies de cactáceas e três espécies folhosas, a saber: Opuntia sp. (Palma), Cereus jamacaru DC. (Mandacaru), Pilosocereus gounellei (F. A. C. Weber) Byles \& G. D. Rowley (Xique-xique), 
Cenostigma bracteosum (Tul.) LP Queiroz (Catingueira), Cnidoscolus quercifolius Pohl. (Faveleira), Aspidosperma pyrifolium Mart. (Pereiro).

Como tratamento controle, utilizou-se o Pinus sp., uma vez que, durante a realização do experimento, ainda não havia na literatura uma espécie da Caatinga com elevada inflamabilidade para servir como testemunha. Dessa forma, com base em estudos realizados com comportamento de fogo e inflamabilidade, utilizou-se o Pinus sp. como testemunha. No entanto, Silva Neto (2017), avaliando inflamabilidade de diferentes fitofisionomias em espécies da Caatinga, constatou a elevada inflamabilidade do capim panasco (Aristida adscensionis L.), sendo considerada a espécie fogo da Caatinga.

Com auxílio de um gabarito, foram delimitadas parcelas com um metro quadrado, sorteando-se os blocos e o material de cada espécie. As parcelas foram organizadas a 1,5m uma da outra, bem como entre blocos, para que não houvesse interferência das chamas entre os tratamentos.

\section{Coleta do material vegetal}

A coleta do material vegetal ocorreu de maneira destrutiva, sendo nas espécies folhosas e do tratamento testemunha, coletadas folhas e galhos com diâmetro $\leq$ a $0,7 \mathrm{~cm}$, a $50 \%$ de proporcionalidade, considerados como combustível os ramos finos das copas (SOARES et al., 2007). Para a classificação do diâmetro do material combustível nas folhosas e na testemunha, utilizou-se um calibrador de diâmetro (Figura 4). Em relação às cactáceas, a mensuração levou em consideração o porte vegetativo das mesmas.

As coletas das amostras das espécies Cenostigma bracteosum (Catingueira), Cnidoscolus quercifolius (Faveleira) e Aspidosperma pyrifolium (Pereiro) foram realizadas na fazenda Nuperárido, pertencente à UFCG/CSTR, Campus de Patos/PB, em fevereiro de 2018. A coleta das amostras de Pinus ocorreu também em fevereiro de 2018, em plantios existentes no município de Areia/PB, pertencentes à Universidade Federal da Paraíba. As coletas de Cereus jamacaru (Mandacaru), Opuntia sp. (Palma) e o Pilosocereus gounellei (Xique-xique) ocorreram em maio de 2018, entre as cidades de Junco do Seridó e Juazeirinho, na Paraíba.

Cada material combustível coletado foi acondicionado em sacos de $60 \mathrm{~kg}$, devidamente identificados. Após a coleta, as amostras de folhosas foram deixadas para secagem durante 90 dias, em um ambiente com circulação de ar no Viveiro Florestal da UFCG, em Patos/PB. Já as cactáceas foram deixadas para secagem durante 15 dias, em um galpão do viveiro.

Definiu-se o período de tempo de secagem (90 dias para as folhosas e 15 para as cactáceas) baseado no clima da região e no comportamento xerófilo e caducifólio das espécies estudadas, uma vez que as susceptibilidades aos incêndios ocorrem na época do ano em que as plantas perdem as folhas, ou seja, na época de escassez de água.

Para as cactáceas, optou-se somente que as mesmas perdessem o excesso de água. Dessa forma, a queima ocorreu com intuito de reproduzir o comportamento do fogo nas parcelas, simulando a ação do incêndio no período de estiagem, para uma melhor homogeneidade do experimento com as condições reais no campo. 


\section{Determinação da umidade do material combustível}

Para determinação da umidade, foram coletadas amostras de cada espécie, sendo estas acondicionadas em sacos plásticos vedados, para impedir a perda d’água, e levadas aos laboratórios de Nutrição de Plantas e Produtos Florestais, nas dependências do Centro de Saúde e Tecnologia Rural (CSTR), Campus de Patos/PB, determinando-se a massa e o teor de umidade.

Assim, retirou-se três amostras de cada tratamento, sendo pesado o material verde para determinar a massa fresca e, em seguida, cada amostra foi transferida para de sacos de papel, sendo colocadas para secar em uma estufa de circulação forçada de ar a 65으, por $72 \mathrm{~h}$. Após esse procedimento as amostras foram pesadas em balança de precisão determinando-se a massa seca. O teor de umidade de cada espécie foi calculado utilizando a seguinte fórmula:

$$
U(\%)=\frac{M F-M S}{M S} * 100
$$

Em que: $U(\%)=$ Umidade do material; $M F=$ Massa fresca; $M S=$ Massa seca.

\section{Características avaliadas do comportamento do fogo}

O comportamento do fogo foi avaliado por meio da queima de dois quilogramas de material combustível seco das folhosas e na testemunha (folhas e ramos finos) e, nas cactáceas, o procedimento adotado foi o preenchimento total do esquadro, espalhados homogeneamente nas parcelas e, posteriormente, realizou-se a pesagem desse material.

Após esse procedimento, mediu-se a temperatura do solo e do material combustível, antes e depois da queima, utilizando-se termômetro digital portátil a laser. A queima dos materiais combustíveis foi realizada ao mesmo tempo e cronometrada do início ao final. Realizou-se a queima diretamente no solo, para simulação da ação do incêndio do material combustível no solo, como ocorre no ambiente natural.

Para a ignição do fogo em cada parcela, usou-se o lança-chamas, devido a sua intensidade, que facilita o processo de ignição e por simular as chamas de um incêndio natural, sendo útil na ação do fogo nos materiais combustíveis como um todo. Durante a realização do experimento, foi registrada a umidade relativa do ar, por meio do aparelho termo higrômetro digital, e a velocidade do vento, com o auxílio do anemômetro, uma vez que, segundo Sant'Anna et al. (2007), a temperatura pode interagir na queima do material combustível e na velocidade de propagação do fogo, pois à medida que se eleva a temperatura do ar, maior será a temperatura do material combustível e menor a necessidade de calor para que este atinja a temperatura de ignição.

Para a avaliação do comportamento do fogo, foram estimados os seguintes parâmetros: Tempo de ignição (TI): tempo em segundos que o material combustível levou para entrar em ignição, registrado com auxílio de cronômetro; Frequência de ignição (FI): número de repetições em que ocorreu ignição; Tempo de duração da queima (TQ): tempo de combustão em segundos do material combustível, também registrado com auxílio de cronômetro; Altura das chamas (HC): foi estimada com auxílio de uma régua graduada, com a fita vermelha marcando a cada $10 \mathrm{~cm}$ e a fita na cor verde marcando os $50 \mathrm{~cm}$. Velocidade de propagação 
(VP): tempo que o fogo leva para queimar um metro do material combustível. Classificação da Velocidade de Propagação: após esse procedimento, a velocidade de propagação foi classificada com base em Botelho et al. (1990), apresentada na Tabela 1.

Tabela 1: Classificação da velocidade de propagação do fogo.

\begin{tabular}{|l|l|}
\hline Velocidade de propagação $\left(\mathrm{m} \mathrm{s}^{-1}\right)$ & Classificação \\
\hline$<0,033$ & Lenta \\
\hline $0,033-0,166$ & Média \\
\hline $0,166-1,166$ & Alta \\
\hline$>1,166$ & Extrema \\
\hline
\end{tabular}

Fonte: Botelho et al. (1990).

Índice de combustibilidade (IC): mensurado com base na média das alturas das chamas, designado conforme a Tabela 2. O índice de combustibilidade constitui um parâmetro novo de avaliação do comportamento do fogo e inflamabilidade de espécies, adaptado de Petriccione (2006). Com base nos trabalhos desenvolvidos na Caatinga por Ribeiro et al. (2012), Bakke (2014), Silva Neto (2017), bem como nos resultados encontrados nesse estudo, foi possível a determinação de um índice para experimento de campo que avalie a combustibilidade, ou seja, a capacidade do fogo de consumir o material e manter a sustentabilidade da queima, em vegetação de Caatinga, por meio da altura das chamas dos materiais combustíveis.

Tabela 2: Índice de combustibilidade (IC) para vegetação de Caatinga.

\begin{tabular}{|l|l|l|}
\hline Índice de combustão (IC) & Designação do IC & Altura da chama $(\mathrm{cm})$ \\
\hline IC1 & Muito baixa & $<10$ \\
\hline IC2 & Baixa & $11-30$ \\
\hline IC3 & Média & $31-60$ \\
\hline IC4 & Alta & $61-120$ \\
\hline IC5 & Muito Alta & $>120$ \\
\hline
\end{tabular}

Fonte: Adaptado de Petriccione, (2006).

- Intensidade do fogo (I): estimada conforme Byran (1959), Soares et al. (2007), de acordo com a fórmula abaixo (2):

$$
I=H \cdot w \cdot r
$$

Em que: $I=$ intensidade do fogo $\left(\mathrm{kW} \mathrm{m}^{-1}\right) ; H=$ poder calorífico do combustível $\left(\mathrm{kj} \mathrm{kg}^{-1}\right) ; w=$ peso do combustível disponível $\left(\mathrm{kg} \mathrm{m}^{-2}\right) ; r=$ velocidade de propagação do fogo $\left(\mathrm{m} \mathrm{s}^{-1}\right)$.

A partir de estudos realizado por Ribeiro et al. (2012), Bakke (2014), Silva Neto (2017), com comportamento do fogo em espécies da Caatinga, bem como com os obtidos nesse estudo, pôde-se designar, com base nos valores da intensidade do fogo, os limites de severidade para danos aceitáveis em espécies florestais da Caatinga, adaptando-se de Shakesby et al. (2006) e McArthur (1967), que se encontram na Tabela 3.

Tabela 3: Intensidade do fogo e nível de aceitação da severidade para espécies florestais da Caatinga.

\begin{tabular}{|l|l|}
\hline Intensidade do fogo $\mathbf{~} W ~ \mathbf{~}^{-1}$ & Severidade \\
\hline$<10$ & Muito baixo \\
\hline $11-41$ & Moderadamente Baixo \\
\hline $42-60$ & Baixo \\
\hline $61-81$ & Moderado \\
\hline $82-112$ & Moderadamente Alto \\
\hline
\end{tabular}




\begin{tabular}{l|l}
$113-143$ & Alto \\
$>143$ & Muito Alto
\end{tabular}

Fonte: Adaptado de Shakesby et al. (2006) e McArthur (1967).

\section{Determinação do poder calorífico e Teor de Cinzas:}

A determinação do poder calorífico superior foi realizada utilizando a bomba calorimétrica de Parr. Para obtenção do poder calorífico, utilizaram-se as mesmas amostras na determinação da umidade, homogeneizando o material combustível, tendo assim a utilização das mesmas plantas na determinação da umidade, na queima e no poder calorífico. Para ser trituradas e moídas, as amostras das cactáceas foram secas em estufa a uma temperatura de $65^{\circ} \mathrm{C}$, por um período de $120 \mathrm{~h}$. Já as folhosas e a testemunha foram secas também na temperatura $65 \stackrel{\circ}{ } \mathrm{C}$, porém, por um período de $72 \mathrm{~h}$, sendo estas armazenadas em um recipiente térmico até o término da secagem das cactáceas, para evitar alteração das propriedades.

Para a obtenção das cinzas, foram colocados em estufa de esterilização e secagem cadinhos de porcelana, durante toda a noite na estufa, dispensando desse modo, a verificação de constância de peso. Em seguida, foram pesadas e os valores anotados para determinação do teor de cinzas conforme equação abaixo:

$$
\text { Cinzas }(\%)=\frac{\text { peso }(\text { cinzas da mufla })}{\text { peso (amostra da estufa a 105ㅇ) }} * 100
$$

O processamento dos dados e as tabelas foram elaborados utilizando-se a planilha eletrônica EXCEL 2013 da Microsoft. As análises estatísticas dos dados obtidos no experimento foram realizadas utilizando o software Sisvar versão 5.6, submetidos à análise de variância aplicando os Testes de SNK para parâmetros de inflamabilidade e Tukey para parâmetros relacionados ao poder calorífico, para comparação de médias, ambos a 5\% de significância.

\section{RESULTADOS E DISCUSSÃO}

\section{Condições meteorológicas}

$\mathrm{Na}$ Tabela 4, encontram-se os dados meteorológicos registrados durante a realização da queima dos materiais combustíveis. Os valores médios da umidade relativa do ar, temperatura e a velocidade do vento, foram: $32,82 \%, 26$ ㄷ $\mathrm{C}$ de $2,99 \mathrm{~m} \mathrm{~s}^{-1}$, Norte, respectivamente; sendo realizada a favor do vento.

Tabela 4: Condições meteorológicas durante a realização da queima dos diferentes materiais combustíveis.

\begin{tabular}{|l|l|l|l|l|}
\hline & & & Variáveis Analisadas & \\
\hline Temperatura (으) & UR* (\%) & $\mathrm{VV}\left(\mathrm{km} \mathrm{h}^{-1}\right)$ & Sorteio das parcelas no bloco & Sequência/ sorteio de blocos + queima \\
\hline \multirow{3}{*}{28} & \multirow{3}{*}{2,92} & $\begin{array}{l}3,2,6,7,1,5 \text { e } 4 . \\
5,4,2,1,6,7 \text { e } 3\end{array}$ & 1 \\
& & & $1,2,5,4,3,7$ e 6 & 2 \\
& & & $6,1,4,7,3,5$ e 2 & 4 \\
\hline
\end{tabular}

UR: Umidade Relativa VV: Velocidade do Vento SQ: Sorteio das parcelas no bloco

* Tratamentos: 1- Opuntia sp., 2- Pinus sp., 3- C. jamacaru, 4- A. pyrifolium, 5- C. bracteosum, 6- P. gounellei e 7- C. quercifolius

As condições meteorológicas apresentaram valores relativamente homogêneos durante a realização da queima, com temperatura média variando entre 26 ㄷ $\mathrm{C}$ e 31 으; umidade relativa do ar entre $29,4 \%$ a $39 \%$ 
e ventos de 2,5 a 3,6 $\mathrm{m} \mathrm{s}^{-1}$. Segundo Soares et al. (2007), quando a velocidade dos ventos estiverem entre 2 e $5 \mathrm{~m} \mathrm{~s}^{-1}$, os mesmos são classificados, de acordo com a escala de Beaufort (PRIMAULT, 1979), como muito fracos, o que favorece para uma lenta propagação do fogo, contribuindo para uma queima homogênea.

\section{Teor de umidade}

As cactáceas somente apresentaram desidratação suficiente para ser constatado o teor de umidade real contido nas mesmas a $120 \mathrm{~h}$ constante em estufa de circulação, sob temperatura de 65 으. Também somente nessa condição foi possível a obtenção de amostras para serem moídas e assim determinar o poder calorífico superior. O elevado teor de armazenamento de água em seus cladódios impediu que fossem moídas em menor tempo de secagem. Os dados obtidos são evidenciados na Tabela 5.

As folhosas e a testemunha (Pinus) permaneceram à temperatura constante de 65으, durante 72 horas, isto porque somente nessa condição, pôde-se determinar o teor de umidade real o material da espécie Cnidoscolus quercifolius (faveleira), bem como para ser moído, devido à presença de látex e ao seu elevado teor de umidade.

Tabela 5: Teor médio de umidade de diferentes materiais combustíveis de folhosas e cactáceas

\begin{tabular}{|l|l|l|l|}
\hline Tratamentos & Nome popular & Umidade 72h em estufa (\%) & Umidade 120h em estufa (\%) \\
\hline Opuntia sp. & Palma & 145,23 & 286,15 \\
\hline Pinus $s p$ & Pinus & 148,27 & - \\
\hline Cereus jamacaru & Mandacaru & 178,34 & 356,86 \\
\hline Aspidosperma pyrifolium & Pereiro & 136,25 & - \\
\hline Cenostigma bracteosum & Catingueira & 79,77 & - \\
\hline Pilosocereus gounellei & Xique-xique & 181,15 & 414,18 \\
\hline Cnidoscolus quercifolius & Faveleira & 224,13 & - \\
\hline
\end{tabular}

O material da Opuntia sp. (palma) registrou o menor valor no teor de umidade entre as cactáceas em estufa a $120 \mathrm{~h}$ com $286,15 \%$, sendo os maiores valores de umidade registrados nos materiais do Pilosocereus gounellei (xique-xique), com 414,18\%, e do Cereus jamacaru (mandacaru), com 356,86 \%. Pode-se observar que a $65^{\circ} \mathrm{C}$ por $72 \mathrm{~h}$ em estufa, com exceção da Cenostigma bracteosum $\mathrm{T}(1)$, que apresentou umidade abaixo dos demais tratamentos. O tratamento com Pilosocereus gounellei (T6) foi o que registrou maior teor de umidade dentre as cactáceas a $72 \mathrm{~h}$ em estufa $(181,15 \%)$. Já entre os demais tratamentos, os valores mais elevados foram encontrados nos tratamentos com pinus (T2), com 148,27\%, e no tratamento com Aspidosperma pyrifolium (T4), com 136,25\%.

A umidade pode influenciar negativamente no material combustível para geração de energia, pois pode alterar na quantidade de calor liberado na combustão, interferindo na eficiência energética. No processo de combustão, parte da energia liberada é aproveitada para evaporar a água referente ao teor de umidade, diminuindo o poder calorífico superior (LIMA et al., 2008).

Para Quirino et al. (2005), o conteúdo de umidade provoca perda de calor nos gases de combustão sob forma de vapor d'água, uma vez que a umidade é evaporada absorvendo energia em combustão. Müzel et al. (2014) também afirmam que o teor de umidade influencia diretamente no potencial energético, pois, quanto maior a umidade, menor será o poder calorífico. 
Segundo Batista et al. (2012), essas diferenças podem ser atribuídas à época de coleta, ao estado fisiológico e ao mecanismo de troca ou permanência das folhas. Para Weir et al. (2014), o teor de umidade do material combustível pode mudar dinamicamente com o clima, porém a composição e estrutura dos materiais combustíveis são mais estáveis sobre o comportamento do fogo.

\section{Comportamento do fogo}

Para análise do comportamento e avaliação da inflamabilidade, inicialmente verificou-se a frequência de ignição do fogo (FI), que consiste na quantidade de vezes que o material combustível foi submetido `as chamas até entrar em ignição, considerando frequência máxima de ignição igual a 3, ao tempo livre, ou seja, tempo que o material levou para entrar em ignição (TI) em segundos (Tabela 6).

Tabela 6: Frequência e tempo de ignição dos materiais combustíveis

\begin{tabular}{|l|l|l|l|}
\hline Tratamentos & Nome popular & Fl (Repetições) & Tempo de Ignição (s) \\
\hline Opuntia sp. & Palma & 3 & $60,07 \mathrm{~b}$ \\
\hline Pinus sp & Pinus & 1 & 1,50 a \\
\hline Cereus jamacaru & Mandacaru & 3 & $66,27 \mathrm{~b}$ \\
\hline Aspidosperma pyrifolium & Pereiro & 2 & 6,75 a \\
\hline Cenostigma bracteosum & Catingueira & 3 & 4,25 a \\
\hline Pilosocereus gounellei & Xique-xique & 3 & $68,79 \mathrm{~b}$ \\
\hline Cnidoscolus quercifolius & Faveleira & 3 & 5,0 a \\
\hline
\end{tabular}

FI: Frequência de Ignição. Letras iguais indicam que, ao nível de 5\%, não existe diferença significativa entre as médias, pelo teste de SNK.

Verificou-se que os materiais combustíveis da palma, do mandacaru, do xique-xique e as parcelas das folhosas catingueira e faveleira obtiveram as frequências máximas, comparadas com as parcelas de pinus, que apresentou a menor frequência dentre os materiais combustíveis para ignição do fogo. A não combustão do fogo nas cactáceas foi evidenciada pela dificuldade de ignição das mesmas, pois apenas os espinhos entraram em combustão, não ocorrendo queima nos cladódios, o que diferiu dos demais tratamentos, resultando em propagação nula do fogo ou sendo consideradas negativas. Não foram encontradas pesquisas relacionadas com as cactáceas como cortina de proteção contra o fogo.

A palma pode conter, em média, $90 \%$ de água em sua composição (SANTOS et al., 2006). Não foram encontrados registros dos teores de água do xique-xique e do mandacaru. Para tanto, estima-se que os mesmos podem conter cerca de 70 a $90 \%$ de água na sua composição, uma vez que as mesmas possuem elevado teor de água armazenada, que constitui seu principal mecanismo de sobrevivência na Caatinga. 0 conteúdo de água existente em um material deve ser expulso para que o mesmo possa entrar em ignição (SOUZA, 2015). Como a composição das cactáceas, em sua maioria, é agua, é necessário, portanto, que haja uma temperatura muito elevada para promover a ignição.

As folhosas apresentaram frequência consideravelmente elevada para ignição do fogo, sendo necessárias duas tentativas para iniciar a combustão para o pereiro, três tentativas para a catingueira e Faveleira. Apesar disso, as folhosas levaram pouco tempo para entrar em ignição quando estas foram submetidas à ação de chamas, apresentando-se estatisticamente semelhantes à testemunha (pinus).

Diferenças na composição das espécies, deterioração do material e a umidade podem atuar para 
determinar a ignição, intensidade da linha de fogo, taxa propagação do fogo e consumo de combustíveis. Essas características de comportamento de fogo são denominadas coletivamente de capacidade de um combustível para queimar (GILL et al., 2005).

O tempo de combustão (TC) que é a sustentabilidade do fogo no material combustível, foi avaliado em todos os tratamentos, diferindo estatisticamente entre si (Tabela 7). 0 tratamento com pinus registrou maior valor, apresentando quase $50 \%$ a catingueira e o pereiro, que foram semelhantes, indicando que, no material combustível dessas espécies da Caatinga, a inflamabilidade é elevada, característica que anula a indicação do uso das mesmas como cortina de vegetação. Nas cactáceas, o TC foi avaliado pela combustão dos espinhos, já que esta foi a única parte que entrou em combustão, e isso reflete nos valores mais baixos das cactáceas em relação às folhosas.

Tabela 7: Valores médios do tempo de combustão em diferentes materiais combustíveis.

\begin{tabular}{|l|l|l|}
\hline Tratamentos & \multicolumn{1}{|c|}{ Nome popular } & Tempo de Combustão (s) \\
\hline Opuntia sp & Palma & 1,25 c \\
\hline Pinus sp & Pinus & 874,50 a \\
\hline Cereus jamacaru & Mandacaru & 3,25 c \\
\hline Aspidosperma pyrifolium & Pereiro & 454,00 b \\
\hline Cenostigma bracteosum & Catingueira & 454,25 b \\
\hline Pilosocereus gounellei & Xique-xique & $1,75 \quad \mathrm{c}$ \\
\hline Cnidoscolus quercifolius & Faveleira & $125,50 \quad \mathrm{c}$ \\
\hline
\end{tabular}

Letras iguais indicam que, ao nível de 5\%, não existe diferença significativa entre as médias, pelo teste de SNK.

Verificou-se que a faveleira não diferiu das cactáceas, o que evidencia a baixa inflamabilidade da espécie. Dentre as folhosas, a faveleira apresentou o maior teor de umidade, o que influenciou na baixa inflamabilidade do material combustível, proporcionando o que se denomina de umidade de extinção do fogo. Foi constatado que os galhos da faveleira não foram totalmente consumidos pelo fogo, enquanto que as folhas foram consumidas em maior proporção. Esse comportamento do fogo nesse material combustível revela que os galhos possuem pouca inflamabilidade em relação às folhas, confirmando a diferença de inflamabilidade entre as partes da planta.

Nas cactáceas, o eficiente armazenamento da água, que é o mecanismo de sobrevivência para a espécie no ambiente xérico, proporcionou a não ignição e inflamabilidade nula desse material combustível em todos os tratamentos, confirmando sua eficiência, não somente como cerca viva contra animais, mas também como cortina de segurança contra incêndios florestais. Assim, fica comprovado, no presente estudo, que a probabilidade de ignição do fogo nesses vegetais é nula.

Para o meio ecológico, a pouca sustentabilidade do fogo nos materiais combustíveis de cactáceas e faveleira, em ambientes semiáridos como a Caatinga, pode influenciar o comportamento do fogo, favorecendo a não propagação do mesmo, o que irá amenizar os impactos do fogo no ecossistema com elevado risco de ocorrência de incêndios florestais, como é a Caatinga. Em relação ao pereiro, verificou-se que os galhos entraram em combustão com maior intensidade, podendo manter a combustão desse material combustível, comportamento contrário ao observado com o material da faveleira.

Bakke (2014), quantificando o material combustível e comportamento fogo em área de caatinga, 
evidenciou o pereiro com baixa inflamabilidade. Como nessa pesquisa ocorreu a quantificação do material combustível no piso florestal e sendo o pereiro uma espécie caducifólia, ocorreu acúmulo de suas folhas na superfície do solo, com poucos vestígios de galhos. Neste caso, a fração que compõe o material combustível em maior quantidade é a de folhas e isso pode reduzir a probabilidade de propagação do fogo.

Conhecer e entender essa dinâmica no ambiente permite considerar um ótimo mecanismo indireto de defesa contra incêndios florestais para as espécies de floresta seca como a Caatinga, devendo outros estudos serem desenvolvidos, levando-se em consideração a composição das folhas, e galhos das espécies vegetais.

Estudos realizados por Clark et al. (2014), para testar a inflamabilidade do combustível de folhas e de serapilheira, constataram que as folhas longas e onduladas tinham maior intensidade de queima, com rápida duração e com potencial de consumir mais combustível. Souza (2015) também enfatiza que a nervura das folhas pode influenciar a inflamabilidade, pois, quanto mais largas e maiores proporções, os teores de água presente na folha também são elevados.

É importante destacar que uma mesma planta pode conter diferença na inflamabilidade entre suas partes e, no caso do presente estudo, isso foi evidenciado em galhos finos, com diâmetros $\leq 0,7 \mathrm{~cm}$ e as folhas presentes nos mesmos. Assim, este estudo reforça a importância de entender os modelos e mecanismos de inflamabilidade presentes nas plantas e sua ação na serapilheira das florestas, como ferramenta de grande relevância para elaboração de programas de prevenção contra o fogo em ecossistemas susceptíveis ao mesmo.

Na Tabela 8, podem ser visualizados os valores da altura da chama (HC) e a designação do índice de combustibilidade (IC), que representa a capacidade que a biomassa vegetal tem de queimar, verificada através da altura da chama, que foi adaptado de Petriccione (2006), para experimentos de campo para espécies de Caatinga utilizadas no presente estudo.

Tabela 8: Altura da chama $(\mathrm{HC})$ em $\mathrm{cm}$, o índice de combustibilidade (IC) e a designação do IC para os materiais combustíveis em área de Caatinga na Paraíba.

\begin{tabular}{|l|l|l|l|l|}
\hline Espécie & Nome popular & HC (cm) & (IC) & Designação do IC \\
\hline Opuntia sp & Palma & 1,00 c & 1 & Muito Baixo \\
\hline Pinus $s p$ & Pinus & $32,50 \mathrm{~b}$ & 3 & Médio \\
\hline C. jamacaru & Mandacaru & 2,00 c & 1 & Muito Baixo \\
\hline A. pyrifolium & Pereiro & $55,00 \mathrm{a}$ & 3 & Médio \\
\hline C. bracteosum & Catingueira & $26,25 \mathrm{~b}$ & 2 & Baixo \\
\hline P. gounellei & Xique-xique & $1,00 \mathrm{c}$ & 1 & Muito Baixo \\
\hline C. quercifolius & Faveleira & $13,75 \mathrm{bc}$ & 1 & Baixo \\
\hline
\end{tabular}

Letras iguais indicam que, ao nível de 5\%, não existe diferença significativa entre as médias, pelo teste de SNK.

Fonte: Adaptado de Petriccione (2006).

O material combustível de Aspidosperma pyrifolium apresentou altura média da chama acima de $55,0 \mathrm{~cm}$, diferindo-se estatisticamente dos demais tratamentos. No entanto, com base no IC, a altura das chamas dessa espécie foi classificada com IC médio, mesma classificação atribuída ao material combustível de pinus e da catingueira, que não apresentaram diferença estatística entre si, com relação à altura da chama.

A combustibilidade de Aspidosperma pyrifolium relacionou-se diretamente pela ação da combustão 
nos galhos, o que eleva a intensidade do fogo do material combustível consumindo-o com maior rapidez, apresentando índice de combustibilidade médio igual a 3 (índice que vai até 5), para ambientes como a Caatinga. Devido ao comportamento do fogo nas galhadas de Aspidosperma pyrifolium, esse material pode ser considerado inflamável no ambiente.

A espécie Cenostigma bracteosum (IC igual a 2), apresentou um baixo índice de combustibilidade, com pouco consumo do fogo nas parcelas e pouca sustentabilidade das chamas, que logo entravam em extinção. No entanto, aspectos similares foram constatados em serapilheira de catingueira, verificados por Ribeiro et al. (2012), constando que as folhas de catingueira presente na serapilheira proporcionaram menor inflamabilidade com relação aos demais tratamentos. Segundo os autores, isso pode ser causado pela composição das folhas ou pela acomodação das mesmas na pilha do material combustível, que impedia a entrada de oxigênio suficiente para manter a sustentabilidade da queima, o que justifica o IC para essa espécie.

Segundo Serger (2015), o arranjo e a carga de material combustível podem causar alterações na altura das chamas, provocando distribuição heterogênea do fogo na área de ocorrência. Molina et al. (2017) destacam que a caracterização o material combustível em campo, em condições reais, é necessário para estimar o potencial de inflamabilidade. Todavia, Schwilk (2015) chama atenção pelo fato de que poucos estudos tentaram avaliar a inflamabilidade usando escala de campo experimentos de fogo, devido a restrições de autorização, segurança e custos. Já o material combustível de Cnidoscolus quercifolius foi semelhante estatisticamente às cactáceas estudadas (IC igual a 1), isso está associado às suas propriedades químicas, como, por exemplo, o seu aspecto leitoso, devido à presença do látex na sua constituição, que pode funcionar como inibidor do fogo.

As cactáceas apresentaram índice de combustibilidade muito baixo igual a 1, pois a altura de suas chamas variara de um centímetro, como foi o caso da Opuntia sp. e do Pilosocereus gounellei, a dois centímetros, como o caso do Cereus jamacaru. A combustibilidade, nesses materiais vegetais, ocorreu apenas nos espinhos, não havendo presença de fogo nos cladódios, apenas o escurecimento dos mesmos, sendo consideradas como plantas não inflamáveis. Dessa forma, a inflamabilidade das espécies está intimamente ligada à capacidade de entrar em ignição e à potencialidade de se manter em combustão, ou seja, a sustentabilidade da queima e a combustibilidade dos materiais evidencia o quanto podem ser consumidos pelo fogo.

White et al. (2010), examinando e realizando a classificação de plantas na Califórnia, com base no comportamento do fogo para seleção de plantas interconexão florestal-urbana, verificaram que a altura da chama (HC) foi considerada como indicador potencial de combustibilidade, enfatizando a importância da HC na avaliação da inflamabilidade.

Silva Neto (2017) verificou em experimento de campo, a elevada potencialidade da inflamabilidade do capim panasco (Aristida adscensionis), utilizando a altura da chama como um dos parâmetros para análise do comportamento do fogo, recomendou a implantação de aceiros onde há predominância desse material 
vegetal, como forma preventiva para evitar a continuidade e impedir a propagação fogo.

Assim, evidencia-se a importância de se conhecer a inflamabilidade das plantas, uma vez que estas são usadas tanto para cerca contra animais, no paisagismo e outros usos, o que pode causar divergências com relação à segurança na proteção contra incêndios. Não é recomendável o uso de uma espécie como cortina de segurança sem o real conhecimento da potencialidade de entrar em ignição e cujo desconhecimento pode levar o proprietário a danos irreparáveis a sua propriedade e ao meio ambiente.

Uma divisória feita com vegetação, para fins quaisquer, de forma avulsa, empírica, sem levar em consideração a inflamabilidade da vegetação, pode colocar em perigo a segurança do local, elevando o risco de incêndio na área. No semiárido brasileiro, plantas do gênero Opuntia são comumente encontradas como forma de proteção contra invasão de animais. Nesse caso, a planta promove também a proteção contra incêndios florestais, porém o intuito do produtor não é a proteção contra ação do fogo, mas sim contra a dos animais. Assim, empiricamente, a propriedade fica segura da ação do fogo na superfície. Na Tabela 9, podese observar a avaliação do comportamento do fogo com relação às variáveis velocidade de propagação e intensidade do fogo, bem como a classificação da velocidade de propagação.

Tabela 9: Médias para as variáveis do comportamento do fogo $(p<0,05)$, durante a queima dos materiais combustíveis.

\begin{tabular}{|c|c|c|c|}
\hline Espécie/material combustível & $\begin{array}{l}\text { Velocidade de propagação } \\
\left(\mathrm{m} \mathrm{s}^{-1}\right)\end{array}$ & $\begin{array}{l}\text { Intensidade } \\
\left(\mathrm{kW} \mathrm{m}^{-1}\right)\end{array}$ & Classificação da velocidade de propagação \\
\hline Opuntia sp & $0,0 \mathrm{~b}$ & $0,0 \mathrm{c}$ & Lenta \\
\hline Pinus $s p$ & $0,04883 \mathrm{a}$ & $133,00 \mathrm{a}$ & Média \\
\hline Cereus jamacaru & $0,0 \quad b$ & $0,0 \mathrm{c}$ & Lenta \\
\hline Aspidosperma pyrifolium & $0,01223 \mathrm{~b}$ & 109,96 a & Lenta \\
\hline Cenostigma bracteosum & $0,00864 \mathrm{~b}$ & $80,68 \mathrm{~b}$ & Lenta \\
\hline Pilosocereus gounellei & $0,0 \quad b$ & $0,0 \quad c$ & Lenta \\
\hline Cnidoscolus quercifolius & $0,00509 \mathrm{~b}$ & 41,79 bc & Lenta \\
\hline
\end{tabular}

Letras iguais indicam que, ao nível de $5 \%$, não existe diferença significativa entre as médias, pelo teste de SNK.

Com relação à velocidade de propagação do fogo, o tratamento testemunha Pinus diferiu estatisticamente dos demais e se enquadrou na classificação de alastramento como média, de acordo com a classificação de Botelho et al. (1990). Os demais tratamentos (folhosas e cactáceas) foram estatisticamente semelhantes, apresentando baixa velocidade de propagação, o que os incluiu na classificação como lenta.

Nas cactáceas não houve propagação do fogo, pois apesar do uso do lança-chamas, consequentemente, não apresentaram intensidade, sendo consideradas não inflamáveis. Com relação as folhosas, nota-se que o material de Cnidoscolus quercifolius (Faveleira) apresenta a menor velocidade de propagação do fogo, seguida da Cenostigma bracteosum (Catingueira) e da Aspidosperma pyrifolium (Pereiro).

Apesar da lenta propagação do fogo nas folhosas (Tabela 9), verificou-se a intensidade elevada do material combustível de Aspidosperma pyrifolium (Pereiro), pela capacidade de queima dos seus galhos, uma vez que possuem maior capacidade de entrar em ignição e de combustibilidade em relação às folhas. Para a Caatinga, isso se torna um fato importante do ponto de vista ecológico, relacionado a incêndios de copa, pois, ao entrarem em ignição, as chamas produzidas nos galhos do pereiro podem consumir a planta por inteiro, já que esta é uma árvore de comportamento caducifólio. Vale ressaltar que o diâmetro dos galhos 
queimados nesse estudo, foi $\leq$ que 0,7 centímetros.

O Aspidosperma pyrifolium (Pereiro) não apresentou diferenças estatísticas da testemunha (Pinus sp) em relação à intensidade do fogo, porém diferiu dos demais tratamentos. Já o material combustível de Cenostigma bracteosum (Catingueira) e Cnidoscolus quercifolius (Faveleira) apresentou semelhança estatisticamente com as cactáceas, sendo esta última a única folhosa a apresentar resultados mais próximos com relação a inflamabilidade com as cactáceas estudadas, comprovando a baixa inflamabilidade do material combustível de Cnidoscolus quercifolius (Faveleira). Neste estudo, constatou-se que a intensidade da queima constitui um dos parâmetros fundamentais na determinação de espécies com inflamabilidade, podendo evidenciar a existência de inflamabilidade em diferentes partes de uma mesma planta, tomando por base a energia liberada por essas partes.

A intensidade constitui a variável de maior importância quando se estuda comportamento do fogo, uma vez que esta evidencia a magnitude da combustão, tornando-se um parâmetro indispensável na avaliação dos efeitos do fogo no meio ambiente (BATISTA et al., 2013). Fieldler et al. (2015) destacam que a reação da combustão está diretamente relacionada com a intensidade do material combustível, para caracterizar o comportamento do fogo.

Neste estudo, o cálculo da intensidade do fogo, apresentados na Tabela 9, evidencia uma associação segura entre altura da chama (Tabela 8) e da intensidade do fogo, apresentando uma variação apenas no tratamento com Pinus em relação à altura chama e à estimativa da intensidade da queima. Entretanto, Santoni et al. (2006) apontam que as variáveis podem apresentar variação nas características avaliadas.

Batista et al. (2013) relataram que é possível obter uma boa estimativa da intensidade do fogo através das dimensões das chamas e que, por isso, é muito usado na comparação de queimas em experimentos com incêndios florestais. A partir dos resultados obtidos com a intensidade do fogo, pode-se simular o grau da severidade dos tratamentos no meio ambiente natural, que constitui a ação do fogo no meio ambiente, ou seja, os impactos no ecossistema. Dessa forma, a severidade foi designada conforme Tabela 3, e os valores apresentados na Tabela 10.

Tabela 10: Nível de aceitação da severidade dos materiais combustíveis da Caatinga.

\begin{tabular}{|l|l|l|l|}
\hline Tratamentos & Nome popular & $\begin{array}{l}\text { Intensidade } \\
(\mathbf{k W ~ m} \mathbf{- 1})\end{array}$ & $\begin{array}{l}\text { Índice } \\
\text { considerado }\end{array}$ \\
\hline Opuntia sp. & Palma & $0,0 \mathrm{c}$ & Muito baixo \\
\hline Pinus sp & Pinus & $133,00 \mathrm{a}$ & Alto \\
\hline Cereus jamacaru & Mandacaru & $0,0 \mathrm{c}$ & Muito baixo \\
\hline Aspidosperma pyrifolium & Pereiro & $109,96 \mathrm{a}$ & Moderadamente Alto \\
\hline Cenostigma bracteosum & Catingueira & $80,68 \mathrm{~b}$ & Moderado \\
\hline Pilosocereus gounellei & Xique-xique & $0,0 \mathrm{c}$ & Muito baixo \\
\hline Cnidoscolus quercifolius & Faveleira & 41,79 bc & Baixo \\
\hline
\end{tabular}

Fonte: Adaptado de Shakesby et al. (2006) e McArthur (1967).

Verificou-se que as cactáceas são as únicas espécies que apresentaram um nível de severidade muito baixo, não apresentando risco de propagação de incêndios. Outro aspecto relevante é o material da espécie Cnidoscolus quercifolius (faveleira), que apresenta um baixo índice de severidade no meio ecológico e, conforme indicam os resultados, mesmo que entre em ignição, a intensidade do fogo é muito baixa, com 
chamas que não causam consumibilidade e, consequentemente, o fogo não se sustenta e se extingue sozinho.

Pode-se observar que o material de Cenostigma bracteosum (catingueira) apresentou nível moderado de severidade do fogo, evidenciando que apesar de não ser considerada como espécie inflamável por Ribeiro et al. (2012) e Bakke (2014), pode apresentar risco na propagação do fogo, dependendo da concentração do material combustível no solo, pois não se conhece sua propagação em grandes concentrações. O material de Aspidosperma pyrifolium (pereiro) foi única folhosa que apresentou grau modernamente alto, uma resposta direta com a intensidade da queima provocada pela combustão dos galhos durante a queima.

Keely (2009) ressalta que os efeitos do fogo são frequentemente variáveis dentro e entre os diferentes ecossistemas e que estimar a intensidade do fogo constitui um parâmetro necessário, pois pode fornecer uma descrição preliminar da gravidade do fogo. Para o autor supracitado, a severidade do fogo refere-se à perda ou decomposição da matéria orgânica acima e abaixo do solo, e as medidas desse parâmetro variam entre os ecossistemas.

Prever como a intensidade ou gravidade do incêndio afetará as respostas é fundamental para o gerenciamento pós-fogo. Reconhecer a importância sobre a severidade do fogo ou da queima e a resposta do ecossistema constitui um argumento que poderia ser colocado em pauta, tanto pelos impactos no meio ambiente ecológico quanto para a sociedade, no entanto, para essas questões, verifica-se a pouca consideração.

Apesar de ser um parâmetro emergente em estudos relacionados com a severidade do fogo na Caatinga, o uso desse parâmetro mostrou-se eficiente quando comparado com a intensidade do fogo das espécies. O parâmetro ainda pode proporcionar o conhecimento das respostas diferenciadas entre as espécies do bioma Caatinga e contribuir com o manejo dos recursos naturais. Verificou-se que, em experimentos de campo, não é comum a medida da temperatura dos materiais combustíveis testados logo após a combustão. Neste estudo, foi constatada a diferença significativa entre os tratamentos.

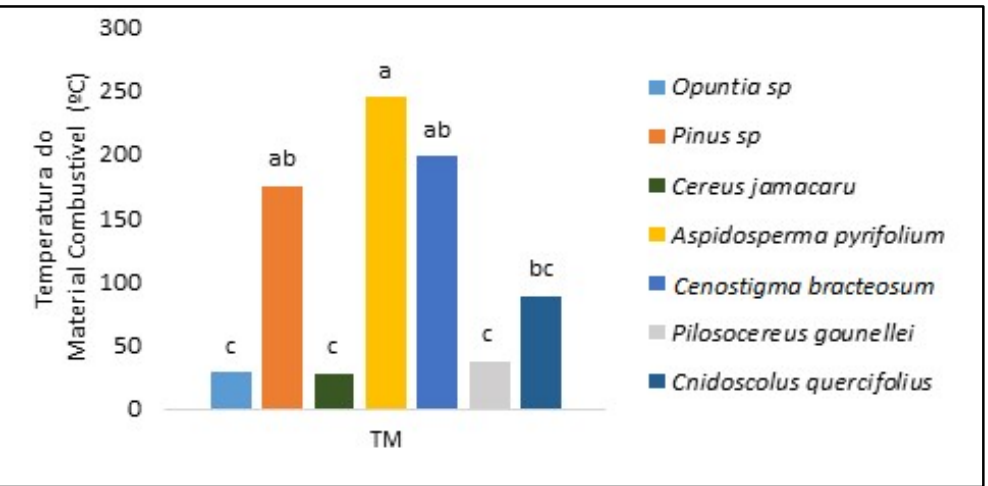

Figura 2: Valores médios da elevação da temperatura do material combustível de cactáceas e folhosas após a queima. Letras iguais indicam que não existe significativa entre as médias, pelo teste SNK, ao nível de 5\% de significância.

Constatou-se que o material de Aspidosperma pyrifolium (pereiro) registrou a maior elevação de temperatura, superando o tratamento testemunha (Pinus), apesar de semelhantes estatisticamente pelo 
teste SNK. A temperatura do material combustível nas parcelas com material de Aspidosperma pyrifolium (pereiro) variou de 190 드, na menor temperatura a 300 드, na maior temperatura registrada pós combustão, enquanto que, nas parcelas com material de Pinus, variou entre $92^{\circ} \mathrm{C}$ a $272^{\circ} \mathrm{C}$. Outro tratamento que superou as temperaturas do tratamento com Pinus foi o material da Cenostigma bracteosum (catingueira), variando entre $152^{\circ} \mathrm{C}$, na menor temperatura, a $216 \circ \mathrm{C}$, na maior temperatura.

As cactáceas foram os tratamentos com as menores médias de temperatura, pós-tentativa de ignição. As temperaturas das cactáceas foram medidas justamente no ponto em que os cladódios estavam escuros, quando sofreram a maior intensidade do fogo do lança-chamas. O material da espécie Opuntia fícus indica (palma) variou entre $21,2^{\circ} \mathrm{C}$ e $36,4^{\circ} \mathrm{C}$ obtendo a menor variação de temperatura entre as cactáceas, sendo que o material do Pilosocereus gounellei (xique-xique) variou entre $30,5 \circ \mathrm{C}$ a $51,0 \circ \mathrm{C}$, e o do Cereus jamacaru (mandacaru) variou de 18,0 으 a 42,0 으.

Houve dificuldade de se compararem os resultados da temperatura dos materiais combustíveis com outros autores, devido à inexistência de trabalhos que avaliassem este parâmetro. No entanto, conhecer a temperatura que os materiais podem atingir permite estimativa da magnitude que esses materiais combustíveis podem causar no ecossistema e determinar medidas preventivas que auxiliam no manejo dos recursos naturais.

Outro fator importante que deve ser levando em consideração é a ação da inflamabilidade da espécie na superfície do solo, pois, dependendo da intensidade e do tempo que o material vegetal permanece em combustão, isso pode acarretar em perdas consideráveis ao meio ambiente. Keely (2009) destaca alguns parâmetros que podem ser avaliados relacionados à severidade do fogo nos solos, que incluem mudanças na estrutura do solo, no crescimento de plantas, na infiltração e retenção de água, escoamento superficial e erosão, que, em muitos casos, são indiretamente relacionados à decomposição da matéria orgânica. Souto (2006) aponta a importância da atividade biológica do solo, pois esta é ocasionada por meio de transformações físicas e químicas da matéria orgânica depositada no solo, agindo como um ciclo que mantém a sustentabilidade dos ambientes.

\section{Poder calorífico superior}

O teor de cinzas e de poder calorífico constituem parâmetros importantes na estimativa da inflamabilidade dos vegetais. Os resultados entre as espécies para cinzas e poder calorífico se encontram na Tabela 11.

Tabela 11: Valores médios para porcentagem de cinzas e poder calorífico materiais combustíveis.

\begin{tabular}{|l|l|l|l|}
\hline Material Combustível & Nome popular & Cinzas (\%) & PCS (Kcal kg-1) \\
\hline Opuntia sp. & Palma & 17,40 & $3.125 \mathrm{c}$ \\
\hline Pinus sp & Pinus & 2,40 & $4.705 \mathrm{a}$ \\
\hline Cereus jamacaru & Mandacaru & 18,81 & $3.519 \mathrm{c}$ \\
\hline Aspidosperma pyrifolium & Pereiro & 11,05 & $4.494 \mathrm{ab}$ \\
\hline Cenostigma bracteosum & Catingueira & 11,79 & $4.661 \mathrm{a}$ \\
\hline Pilosocereus gounellei & Xique-xique & 15,46 & $3.234 \mathrm{c}$ \\
\hline Cnidoscolus quercifolius & Faveleira & 9,92 & $4.105 \mathrm{~b}$ \\
\hline
\end{tabular}

Letras iguais indicam que, ao nível de 5\%, não existe diferença significativa entre as médias, pelo teste de Tukey. 
As cactáceas apresentaram maiores teores de cinzas em relação aos demais tratamentos, e os menores resultados relacionados ao poder calorífico, mesmo com o maior tempo em estufa, diferindo estatisticamente das folhosas e do Pinus. O poder calorífico das cactáceas obteve pouca variação entre as mesmas (palma, com $3.125 \mathrm{Kcal} \mathrm{kg}^{-1}$, mandacaru, com $3.519 \mathrm{Kcal} \mathrm{kg}^{-1}$, xique-xique, com $3.234 \mathrm{Kcal} \mathrm{kg}^{-1}$ ), apresentando baixo poder calorífico. No entanto, a presença dos espinhos pode ter contribuído para elevar o poder calorífico das amostras.

O material do Pinus foi o que apresentou menor teor de cinzas $(2,4 \%)$ e maior poder calorífico $(4.705$ Kcal $\mathrm{kg}^{-1}$ ), evidenciando sua elevada inflamabilidade. Dentre as folhosas, o material da Cenostigma bracteosum (catingueira) apresentou maior teor de cinzas (11,79\%) e maior poder calorífico $\left(4.661 \mathrm{Kcal}^{\mathrm{kg}}\right.$ $\left.{ }^{1}\right)$, o que confirma um bom potencial para geração de energia em folhosa, comprovando que a madeira dessa espécie possui alta inflamabilidade, além de apresentar semelhança estatisticamente com o material do Pinus para a variável poder calorífico.

A Cenostigma bracteosumé única espécie das folhosas estudadas em que a madeira é habitualmente utilizada no Nordeste como lenha para uso doméstico e na fabricação de carvão. Isso demostra que os produtores têm o conhecimento empírico de que a espécie possui madeira de valor comercial pela sua boa capacidade de queima.

O material do Aspidosperma pyrifolium obteve valor do poder calorífico semelhante estatisticamente ao tratamento testemunha (Pinus), com $4.494 \mathrm{Kcal} \mathrm{kg}^{-1}$, e teor de cinzas $11,05 \%$. O poder calorífico dessa espécie está dentro do considerável em folhosas para geração de energia (4.312 a $5.085 \mathrm{kcal} \mathrm{kg}^{-1}$ ), o que confirma a inflamabilidade do lenho da planta.

O material da Cnidoscolus quercifolius apresentou menor teor de cinzas entre as folhosas $(9,92 \%)$ e menor poder calorífico superior, com $4.105 \mathrm{kcal} \mathrm{kg}^{-1}$, permanecendo com poder calorífico abaixo do considerável para energia em folhosas, porém estatisticamente semelhante à Aspidosperma pyrifolium (pereiro). Para tanto, evidencia-se que a faveleira constitui uma planta de baixa inflamabilidade;

As cinzas são compostas de potássio (K), silício (Si), magnésio $(\mathrm{Mg})$, ferro $(\mathrm{Fe})$, cálcio (Ca), sódio ( $\mathrm{Na})$, enxofre $(S)$ e fósforo $(P)$. Quando em alta concentração, podem diminuir o poder calorífico, devido à perda de energia. Para tanto, sua presença pode afetar a transferência de calor (KLAUTAU, 2008). Hoffmann (2010) evidencia que o teor de cinzas também pode interferir no poder calorífico e pode causar perda de energia. Os teores de cinzas encontrados neste estudo são elevados, no entanto, em nativas, o teor de cinzas pode ser maior.

Os valores encontrados nesses estudos referentes aos teores de cinzas são muito superiores aos encontrados por Santos et al. (2013). Quanto ao poder calorífico os resultados dos autores supracitados foram superiores no material de Aspidosperma pyrifolium e inferiores no material da Poincianella pyramidalis.

Medeiros Neto et al. (2014) avaliaram as relações entre as características da madeira e do carvão vegetal da catingueira (Poincianella pyramidalis) e Pau D'árco (Handroanthus impertiginosus) e encontraram, 
respectivamente teores de cinzas de 5,27\% e 1,96\%, e poder calorífico de $6.247,80 \mathrm{kcal} \mathrm{kg}^{-1}$ e $6.977,40 \mathrm{kcal}$ $\mathrm{kg}^{-1}$. Jesus et al. (2017) encontraram resultados similares às folhosas em estudos com eucalipto, com poder calorífico variando de $4538 \mathrm{kcal} \mathrm{kg}^{-1}$ a $4669 \mathrm{kcal} \mathrm{kg}^{-1}$ e teor de cinzas variando entre 0,68\% e 2,85\%, sendo classificadas com boas características para uso em energia.

A inflamabilidade em campo aliada a experimentos laboratoriais fornece maior comprovação dos resultados observados em campo, o que pode impulsionar o desenvolvimento de pesquisas relacionadas a incêndios florestais no Nordeste, principalmente na Caatinga, uma vez que são escassos os trabalhos desenvolvidos.

\section{CONCLUSÕES}

As espécies da Caatinga respondem de maneira diferenciada à ação do fogo, principalmente entre as partes constituintes das plantas, podendo retardar ou catalizar a ação do fogo. As cactáceas Opuntia sp., Cereus jamacaru, Pilosocereus gounellei apresentam inflamabilidade nula, sendo recomendadas em cortinas de segurança, sobretudo contra incêndios de superfície.

A espécie Cnidoscolus quercifolius é uma planta com baixa inflamabilidade sendo recomendada para uso como cortina de segurança, sobretudo contra incêndios de copa, no entanto é preciso manter a área sob manejo, realizando-se a limpeza das folhas secas no solo. As cactáceas e a espécie Cnidoscolus quercifolius são muito importantes na recuperação de áreas no semiárido, uma vez que podem diminuir e/ou assegurar a área em maiores proporções contra os riscos de incêndios. Assim, a diminuição dessas espécies no ecossistema pode elevar os riscos de incêndios florestais.

As espécies Aspidosperma pyrifolium e Cenostigma bracteosum não são indicadas em cortinas de segurança, pois apresentam riscos potenciais devido ao elevado poder calorífico do lenho. A metodologia dos índices de combustibilidade e de severidade do fogo é indicada para estudos posteriores de inflamabilidade e comportamento do fogo em espécies da Caatinga.

\section{REFERÊNCIAS}

ALVARES, C. A.; STAPE, J. L.; SENTELHAS, P. C.; GONÇALVES, J. L. M.; SPAROVEK, G.. Köppen's climate classification map for Brazil. Meteorologische Zeitschrift, v.22, n.6, p.711-728, 2014. DOI: http://doi.org/10.1127/0941-2948/2013/0507

BAKKE, E. A.. Quantificação do material combustível florestal e comportamento do fogo de diferentes ambientes na Paraíba. Monografia (Bacharelado em Engenharia Florestal) - Universidade Federal de Campina Grande, Patos, 2014.

BATISTA, A. C.; BEUTLING, A.; RIBEIRO, J. F.. Estimativa do Comportamento do Fogo em Queimas Experimentais Sob Povoamentos de pinus elliottii. Revista Árvore, Viçosa, v.37, n.5, p.779-787, 2013.

BATISTA, A. C.; BIONDI, D.; TETTO, A. F.; ASSUNÇÃO, R.; TRES, A.; TRAVENISK, R. C. C.; KOVALSYKI, B.. Evaluation of the Flammability of Trees and Shrubs Used in the
Implementation of Green Barriers in Southern Brazil. General Technical Report PSW-GTR-245. In: INTERNATIONAL SYMPOSIUM ON FIRE ECONOMICS, PLANNING, AND POLICY: CLIMATE CHANGE AND WILDFIRES, 4. Anais. Mexico City, 2012.

BOTELHO, H.; VENTURA, J.. Modelos de comportamento do fogo. In: REGO, F. C.; BOTELHO, H.. A técnica do fogo controlado. Universidade de Trás-Os-Montes e Alto Douro, 1990. p.49-55.

BYRAN, G. M.. Combustion of forest fuels. In: DAVIS, K. P.. Forest fire control and use. New York: McGraw-Hill Book Co. 1959.

CLARK, P. J.; PRIOR, L. D.; FRENCH, B. J.; VINCENT, B.; KNOX, K. J. E.; BOWMAN, D. M. J. S.. Using a rainforest-flame forest mosaic to test the hypothesis that leaf and litter fuel flammability is under natural selection. Oecologia, Berlin, 
v.176, n.4, p.1123-1133, 2014. DOI:

http://dx.doi.org/10.1007/s00442-014-3071-y

FIELDLER, N. C.; CANZIAN, W.P.; MAFIA, R. G.; RIBEIRO, G. A.; KRAUSE JUNIOR, J.. Intensidade de queima de diferentes retardantes de fogo. Revista Árvore, v.39, n.4, p.691-696, 2015. DOI: http://doi.org/10.1590/0100$\underline{67622015000400011}$

GILL, A. M.; ZYLSTRA, P.. Flammability of Australian forests. Australian Forestry, Canberra, v.68, n.23, p.87-9, 2005. DOI: http://doi.org/10.1080/00049158.2005.10674951

HOFFMANN, B. S.. O Ciclo Combinado com Gaseificação Integrada e a Captura de CO2: Uma Solução para Mitigar as Emissões de $\mathrm{CO} 2$ em Termelétricas a Carvão em Larga Escala no Curto Prazo. Mestrado (Dissertação) - Universidade Federal do Rio de Janeiro, Rio de Janeiro, 2010.

JESUS, M. S.; COSTA, L. J.; FERREIRA, J. C.; FREITAS, F. P.; SANTOS, L. C.; ROCHA, M. F. V.. Caracterização energética de diferentes espécies de Eucalyptus. Revista Floresta, v.47, n.1, p.11-16, 2017. DOI:

http://dx.doi.org/10.5380/rf.v47i1.48418

KEELY, J.. Fire intensity, fire severity and burn severity: A brief review and suggested usage. International Journal of Wildland Fire, v.18, p.116-126, 2006 DOI:

http://dx.doi.org/10.1071/WF07049

KLAUTAU, P.. Análise experimental de uma fornalha a lenha de fluxo corrente para secagem de grãos. Mestrado (Dissertação em Engenharia de Recursos Hídricos e Ambiental) - Universidade Federal da Paraíba, Curitiba, 2008.

LIMA, E. A.; ABDALA, E. M.; WENZEL, A. A.. Influência da Umidade no Poder Calorífico Superior da Madeira. Colombo, 2008.

NUNES, J. R. S.. FMA: um novo índice de perigo de incêndios florestais para o estado do Paraná- Brasil. Tese (Doutorado em Ciências florestais) - Universidade Federal do Paraná, Curitiba, 2005.

MCARTHUR, A. G.. Fire behaviour in eucalypt forests. Canberra: Forestry and Timber Bureau, 1967.

MEDEIROS NETO, P. N.; OLIVEIRA, E.; PAES, J. B.. Relações entre as Características da Madeira e do Carvão Vegetal de duas Espécies da Caatinga. Floresta e Ambiente, v.21, n.4, p.484-493, 2014. DOI: http://dx.doi.org/10.1590/2179$\underline{8087.051313}$

MOLINA, J. R.; MARTÍN, T.; RODRÍGUEZ, Y.; SILVA, F.; HERRERA, M. A.. The ignition index based on flammability of vegetation improves planning in thewildland-urban interface: Acase study in Southern Spain. Landscape and urban Planning, v.158, p.129-138, 2017. DOI:

http://10.1016/j.landurbplan.2016.11.003 MÜZEL, S. D.; OLIVEIRA, K. A.; HANSTED, F. A. S.; PRATES, G. A.; GOVEIA, D.. Poder calorífico da madeira de Eucalyptus grandis e da Hevea brasiliensis. Brazilian Journal of Biosystems Engineering, v.8, n.2, p.166-172, 2014.
PETRICCIONE, M.. Infiammabilità della lettiera di diverse specie vegetali di ambiente Mediterraneo. Tese (Doutorado em Biologia Aplicada) - Università Degli Studi Di Napoli Federico II, Napoli, 2006.

PRIMAULT, B.. Wind measurement. In: SEEMANN, J.; CHIRKOV, Y. I.; LOMAS, J.; PRIMAULT, B.. Agrometeorology. Heidelberg: Spring-Verlag, 1979. p.84-96.

QUIRINO, W. F.; VALE, A. T.; ANDRADE, A. P. A.; ABREU, V. L. S.; AZEVEDO, A. C. S.. Poder calorífico da madeira e de materiais lignocelulósicos. Revista da Madeira, n.89, p.100106, 2005.

RIBEIRO, T. O.; SOUTO, P. C.; SOUZA, B. V.; SOUTO, J. S.; MARACAJÁ, P. B.. Floor quantification of fuel on the forest in the semiarid region of Paraiba, Brazil. Revista Verde, v.7, n.2, p.50-59, 2012.

SANT'ANNA, C. M.; FIEDLER, N. C.; MINETTE, L. J.. Controle de incêndios florestais. Alegre: Suprema, 2007.

SANTONI, P. A.; SIMEONI, A.; ROSSI, J. L.; BOSSEUR, F.. Instrumentation of wildland fire: Characterization of a fire spreading through a Mediterranean shrub. Fire Safety Journal, v.41, p.171-184, 2006. DOI: http://dx.doi.org/10.1016/j.firesaf.2005.11.010

SANTOS, D. C.; FARIAS, I.; LIRA, M. A.; SANTOS, M. V. F.; ARRUDA, G. P.; COELHO, R. S. B.; DIAS, F. M.; MELO, J. N.. Manejo e utilização da palma forrageira (Opuntia e Nopalea) em Pernambuco. Recife: IPA, 2013.

SCHWILK, D. W.. Dimensions of plant flammability. New Phytol, v.206, p.486-488, 2015. DOI:

http://dx.doi.org/10.1111/nph.13372

SERGER, C. D.. Material combustível e comportamento do fogo em vegetação de estepe gramíneo-lenhosa na RPPN Caminho das Tropas, Palmeira, Paraná. Tese (Doutorado em Engenharia Florestal) - Universidade Federal da Paraíba, Curitiba, 2015.

SHAKESBY, R. A.; DOERR, S. H.. Wildfire as a hydrological and geomorphological agent. Earth Science Reviews, n.74, p.269-307, 2006. DOI:

http://dx.doi.org/10.1016/j.earscirev.2005.10.006

SILVA NETO, F. R. G.. Quantificação do material combustível florestal e comportamento do fogo de diferentes ambientes na Paraíba. Monografia (Bacharelado em Engenharia Florestal) - Universidade Federal de Campina Grande, Patos, 2017.

SOARES, R. V.. Novas tendências no controle de incêndios florestais. Revista Floresta, v.30, n.1-2, p.11-21, 2000. DOI: http://dx.doi.org/10.5380/rf.v30i12.2363

SOARES, R. V.; BATISTA, A. C.. Incêndios florestais: controle, efeitos e uso do fogo. Curitiba: UFPR, 2007.

SOUTO, P. C.. Acumulação e decomposição da serapilheira e distribuição de organismos edáficos em área de caatinga na Paraíba, Brasil. Tese (Doutorado em Agronomia) Universidade Federal da Paraíba, Areia, 2006. 
SOUZA, M. A.. Levantamento de plantas de baixa inflamabilidade em áreas queimadas de cerrado no Distrito Federal e análise das suas propriedades físicas. Dissertação (Mestrado Ciências Florestais) - Universidade de Brasília, Brasília, 2015.

WEIR, J. R.; LAMB, R. F.. Seasonal variation in flammability characteristics of Quercus marilandica and Quercus stellata leaf litter burned in the laboratory. Fire Ecology, v.9, n.3, p.80-8, 2014. DOI:

http://dx.doi.org/10.4996/fireecology.0903080

WHITE, R. H.; ZIPPERER, W. C.. Testing and classification of individual plants for fire behaviour: plant selection for the wildland-urban interface. International Journal of Wildland Fire, v.19, n.2, p.213-22, 2010. DOI:

http://dx.doi.org/10.1071/WF07128

A CBPC - Companhia Brasileira de Produção Científica (CNPJ: 11.221.422/0001-03) detém os direitos materiais desta publicação. Os direitos referem-se à publicação do trabalho em qualquer parte do mundo, incluindo os direitos às renovações, expansões e disseminações da contribuição, bem como outros direitos subsidiários. Todos os trabalhos publicados eletronicamente poderão posteriormente ser publicados em coletâneas impressas sob coordenação da Sustenere Publishing, da Companhia Brasileira de Produção Científica e seus parceiros autorizados. Os (as) autores (as) preservam os direitos autorais, mas não têm permissão para a publicação da contribuição em outro meio, impresso ou digital, em português ou em tradução. 